\title{
Research Paper: Life Changes of the Elderly After Earthquake: A Qualitative Study in Iran
}

\author{
Hamid Reza Khankeh $^{1 *}$ (D), Shokoufeh Ahmadi ${ }^{1}$, Robab Sahaf $^{1}$, Asghar Dalvandi ${ }^{1}$, Seyed Ali Hosseini
}

1. Health in Emergency and Disaster Research Center, University of Social Welfare and Rehabilitation Sciences, Tehran, Iran.

\begin{tabular}{|c|c|}
\hline $\begin{array}{l}\text { Use your device to scan } \\
\text { and read the article online }\end{array}$ & ditat on: Khankeh HR, Ahmadi S, Sahaf R, Dalvandi A, Hosseini SA. Life Changes of the Elderly After Earthquake: A Qualitative \\
\hline 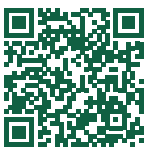 & $\begin{array}{l}\text { Study in Iran. Health in Emergencies and Disasters Quarterly. 2020; 6(1):9-16. http://dx.doi.org/10.32598/hdq.6.1.147.1 } \\
\text { doif: } \text { : http://dx.doi.org/10.32598/hdq.6.1.147.1 }\end{array}$ \\
\hline
\end{tabular}

\section{(i) (5)}

Article info:

Received: 05 Apr 2020

Accepted: 23 Jun 2020

Available Online: 01 Oct 2020

\section{Keywords:}

Accidents, Disasters, Elderly, Earthquake, Qualitative study

\section{ABSTRACT}

Background: The growth of the elderly population, on the one hand, and the increase in exposure to accidents and disasters, on the other hand, have highlighted the attention on the issues of the older adults in disasters. This study aimed to investigate the changes in the lives of the elderly after the earthquake.

Materials and Methods: The present qualitative study was conducted using the content analysis method. The study data were collected through in-depth and semi-structured interviews. In total, 26 participants were interviewed in this study, including 4 specialists (an accident and disaster specialist, an elderly specialist, a psychologist, a social worker), 18 older adults, and 4 caregivers of the older adults. The data collection and data analysis process were performed simultaneously, and the Granheim and Lundman approach was used in this regard.

Results: In this study, two main categories were found about changes in the lives of the elderly after the earthquake: re-victimization and post-accident growth. Re-victimization category consisted of the subcategories of "increased dependency", "declining physical and mental health", "poverty and deprivation", and "avoidance of work and family activities", and post-accident growth included the subcategories of "individual growth", "self-regulatory behaviors", and "reinforcing the houses".

Conclusion: Clarifying the nature and life changes of the elderly after the earthquake can enhance the knowledge of service providers. This information helps them make the necessary plans to prevent and reduce the problems that the elderly face after the earthquake.

\section{Introduction}

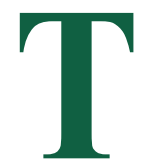

he world's population is aging, and so new problems will be created. In 2000, the world's population aged 60 and over was 600 million. In 2025 , the population is expected to reach 1.2 billion, and in 2050 to 1.9 billion; in developing countries, where $80 \%$ of the elderly live, this ratio increases from $7 \%$ to $12 \%$ of the entire population [1]. Statistical indicators show that the aging population of Iran is also expanding; it is predicted that the percentage of older adults in Iran will reach $10 \%$ of the total population by 2025 and more than $30 \%$ by 2050 [2].

On the other hand, in recent decades, the incidence of accidents and disasters has increased [3]. In 2018, 315

\section{* Corresponding Author:}

Hamid Reza Khankeh, PhD.

Address: Research Center of Health in Emergency and Disasters, University of Social Welfare and Rehabilitation Sciences, Tehran, Iran. E-mail: hamid.khankeh@ki.se 
natural disasters with 11804 deaths affected 68 million people and resulted in $\$ 131.7$ economic losses. Asia was most affected by accidents, accounting for $45 \%$ of accidents, $80 \%$ of deaths, and $76 \%$ of affected people [4].

The growth of the elderly population, on the one hand, and the increase in exposure to accidents and disasters, on the other hand, makes it essential to pay attention to the issues of the elderly in disasters.

In particular, this group suffers disproportionately in many incidents due to age-related physical and cognitive weaknesses and social factors such as social inequality [5]. For example, the highest death toll in North Korea floods in 2018 was recorded among the elderly. Also, in the 2018 British heatwave, 633 deaths were reported among the elderly [6]. In Hurricane Katrina, 56\% of people admitted to medical units were elderly, and in Louisiana, $71 \%$ of deaths occurred in people over 60 [7]. In the earthquake in Azerbaijan Province, Iran, most of the dead were older people [8]. However, most of this group's issues and concerns are ignored in accidents [9].

On the other hand, to minimize the vulnerability of the elderly and provide effective programs and policies, we need to fully understand their specific needs and behaviors and identify the risk factors that result in their injuries.

This study is part of larger research to investigate the process of returning the elderly to life after an earthquake. With a qualitative approach, this study explores the experiences of the elderly living in the community through first-hand experiences during the 18 months after the earthquake in Azerbaijan Province, Iran, which occurred in northeastern Iran in 2012.

\section{Materials and Methods}

This study was conducted to explain the changes in the lives of the elderly after the earthquake. We used qualitative content analysis to collect and analyze data by a conventional method. In conventional content analysis, pre-existing theories have no place, and through induction, categories are extracted from textual data. Thus, the researcher will gain a deeper understanding of the phenomenon [10].

Purposive sampling was used in this study, and participants included earthquake-stricken older people, their caregivers, and specialists. In total, in this study, 26 participants were enrolled, including 4 specialists and 18 older adults who were 60 years or older at the time of the earthquake and 4 caregivers of the elderly. The mean age of the studied elderly was 72.6 years, and to observe maximum diversity, we tried to interview a wide range of older people from different ages and social groups, and sampling continued until data saturation (Table 1).

The interview began with a general question that had an open and descriptive answer. The individuals' responses guided the interview process to achieve the main goal of the research. Some questions in these interviews were as follows: "What problems did you face after the earthquake?" and "What were the differences between your life before and after the earthquake?". The average duration of the interviews was 56 minutes.

The analysis was performed simultaneously with data collection in a comparative and continuous manner. The data analysis process was performed according to Granheim and Lundman approach. Immediately after the interview, and listening to it several times, the entire text of the interview was read several times to gain a general understanding. Then the semantic units were determined, and the initial codes were extracted. Similar primary codes were classified into more general classes, and finally, the main categories were determined.

There were more than one and a half years of data engagement during the study to increase the data's validity. The findings of the analysis were also returned to the participants to ensure the accuracy of the codes and interpretations. Besides, the interviews were conducted. The experts in qualitative research reviewed the relevant codes, concepts, and categories.

This study was reviewed and approved by the Ethics Committee of the University of Social Welfare and Rehabilitation Sciences. At the beginning of the interviews, the participants were fully explained about the research objectives, the methods used, the information confidentiality, and their freedom to leave the study. The time and place of the interviews were also coordinated with the participants.

\section{Results}

The purpose of this study is to explore the situation of the elderly after the earthquake. According to the participants' experiences, the situation of the elderly after the quake was classified into two main categories: re-victimization and post-accident growth. It should be noted that according to the data analysis, each older adult was generally faced with a range of variable outcomes ranging from a decline in some aspects to growth and improvement in others. And the two-category classification of returning to life after an earthquake did not necessar- 
ily mean one type of permanent condition for one older adult and another for another older adult. According to personality factors, situation, and temporal and spatial conditions, a range of these consequences could be seen in the elderly.

\section{Re-victimization}

The concept of re-victimization, which was derived from the analysis of participants' experiences, meant that in addition to the vulnerabilities that existed before the earthquake and caused a great deal of harm to the elderly, postearthquake problems such as resource scarcity, inefficient management, ignoring the elderly, neglecting the unique needs of the elderly and anti-aging had caused or intensified harm to the elderly. The re-victimization category consists of the subcategories "increased dependency", "declining physical and mental health", "poverty and deprivation", and "avoidance of work and family activities".

\section{Declining physical-mental health}

Declining of health was due to the worsening of former physical-mental problems or injuries caused by earthquakes in the elderly.

Loss of mood, sadness, the persistence of fear, anxiety and insecurity, frustration, boredom, sleep problems, and distractions were among the psychological problems mentioned by the elderly.

One of the older adults said about the fear and anxiety after the quake:

"I was in the bathroom at the time of the earthquake. I was alone. I was all dressed upside down out of fear. Now that it's getting windy or a heavy car is passing, I get afraid. I say an earthquake has come. I am afraid of taking a bath and being alone in the bath; the people should come and visit me all the time" (75-year-old woman).

\section{Avoiding work and family activities}

According to the experiences of the participants, some older adults gave up their work and family activities after the earthquake. These activities include giving up work activities, not taking care of home affairs, and reducing interactions with family:

"Every year, when I was working hard, and my products got prepared, I had the joy of going to harvest them and re-cultivate them. But this year, when the earthquake hit, I did not go to my farm. I did not collect what was left of my cultivation and left it to itself'. (68- year-old man).
The son of an elderly said: "My mother used to be active and helped my wife. She used to cook vows with my wife and neighbors. Now she withdraws from everything and does not include herself'. (42-year-old caregiver).

\section{Increased dependency}

Some elderly experienced a temporary or permanent increase in their dependency after the earthquake. Some, due to new needs such as government grants, completion of construction work, etc., temporarily became more dependent on others. On the other hand, in some cases, there were older adults whose dependency permanently increased after the earthquake. For example, some older adults were physically injured and even needed help in daily life. Some were unemployed due to loss of jobs and property and were financially dependent on the help of their children or the Relief Committee.

"Now I have to get money from the Relief Committee and live on it. Before the earthquake, I was working. I had cattle and sheep. I was living on it, and I could easily live on it. When the earthquake struck, some of my animals fell under the rubble. I sold some for a low price, and my hand was empty" (71-year-old woman).

"The earthquake hit me. I was at home, and the roof fell on my legs and waist. I was independent before the earthquake, but now I even have to reach the bathroom with a cane and with the help of my daughter" (77-year-old woman).

\section{Poverty and deprivation}

In addition to the deprivation experienced by almost all groups after the earthquake, the elderly also faced relative poverty and deprivation, which means deprivation compared to other age groups due to factors such as anti-aging and physical disability. Examples of relative housing deprivation for the elderly were lack of independent housing or inadequate housing with incomplete physical reconstruction.

"My mother's house was next to the valley. When the earthquake stroke, her house was destroyed, and they did not give her a house. We had to reconstruct our last house, which was half-ruined, with plaster so that she could live there. Now you see that the house is very dark and smells damp, but she had no choice". (38-year-old, caregiver).

"We used to have animals, and we were not in a bad financial situation, but most of them were killed in the earthquake, and we lost our assets. I could not start again like young people" (62-year-old man). 
Table 1. Demographic characteristics of participants in the study of life changes in the elderly after earthquake

\begin{tabular}{|c|c|c|c|c|c|c|}
\hline Row & Participant & Age (y) & Gender & $\begin{array}{l}\text { Marital } \\
\text { status }\end{array}$ & Education & Job \\
\hline 1 & $\begin{array}{l}\text { Accident and disaster } \\
\text { specialist }\end{array}$ & 48 & Man & Married & Post-doctoral & Professor \\
\hline 2 & Elderly specialist & 43 & Female & Married & PhD. & Professor \\
\hline 3 & Elder & 72 & Man & Widow & Primary school & Shopkeeper \\
\hline 4 & Elder & 84 & Female & Widow & Illiterate & Unemployed \\
\hline 5 & Elder & 82 & Female & Widow & Illiterate & Unemployed \\
\hline 6 & Elder & 86 & Man & Widow & Primary school & Unemployed \\
\hline 7 & Elderly caregiver (child) & 42 & Man & Married & Primary school & Manual worker \\
\hline 8 & $\begin{array}{l}\text { Elderly caregiver } \\
\text { (grandchild) }\end{array}$ & 22 & Female & Widow & Bachelor's degree & Student \\
\hline 9 & Elderly caregiver (child) & 38 & Female & Married & Bachelor's degree & Employee \\
\hline 10 & Elderly caregiver (child) & 42 & Female & Married & Diploma & Housewife \\
\hline 11 & Elder & 62 & Man & Married & Primary school & $\begin{array}{l}\text { Unemployed / Former } \\
\text { livestock }\end{array}$ \\
\hline 12 & Elder & 75 & Female & Widow & Primary school & Unemployed \\
\hline 13 & Elder & 61 & Female & Widow & High school & Housewife \\
\hline 14 & Elder & 83 & Man & Widow & Primary school & Unemployed \\
\hline 15 & Elder & 65 & Female & Married & Illiterate & Farmer \\
\hline 16 & Elder & 67 & Man & Married & Illiterate & Farmer \\
\hline 17 & Elder & 66 & Man & Married & High school & Farmer \\
\hline 18 & Elder & 68 & Man & Married & Illiterate & Livestock \\
\hline 19 & Elder & 64 & Female & Married & High school & Housewife \\
\hline 20 & Elder & 82 & Man & Married & Illiterate & Unemployed \\
\hline 21 & Elder & 77 & Female & Widow & Primary school & Unemployed \\
\hline 22 & Elder & 75 & Female & Married & Primary school & Housewife \\
\hline 23 & Elder & 67 & Man & Married & High school & $\begin{array}{l}\text { Unemployed / Former } \\
\text { rancher }\end{array}$ \\
\hline 24 & Elder & 72 & Female & Married & Primary & Livestock \\
\hline 25 & $\begin{array}{l}\text { Accident and disaster } \\
\text { specialist }\end{array}$ & 38 & Female & Single & PhD. & University lecturer, Manager \\
\hline 26 & $\begin{array}{l}\text { Psychologist (Specialist in } \\
\text { accidents and disasters) }\end{array}$ & 40 & Man & Single & PhD. & Psychologist \\
\hline
\end{tabular}




\section{Growth after the accident}

Another major category in this study is post-accident growth, which includes the early stages of individual development, self-regulatory behaviors, and home resilience.

\section{Individual growth}

Some elderly said that experiencing stressful psychological and physical conditions caused by earthquakes has led to improvements in their relationships with others, focusing on the remaining positive aspects, increased trust, and acceptance of events in their lives. Besides, according to the participants' opinions, using the expertise of the elderly, especially the young elderly who had maintained their skills, strengthened their sense of worth and self-confidence.

"Ambulances were stuck on the road. I took a few injured people in my pickup truck and delivered them to ambulances. Few people like me know the roads. After the earthquake, I helped the rescuers. I showed them the houses of the people who lived alone. They did not know the roads. I showed them, and I was happy that I could save some people" (66-year-old man).

Regarding accepting events and improving relationships with others, one of the elderly said:

"I had seen an earthquake before, not like this. This time that earthquake happened, and I saw how everything turned upside down, and I said to myself that you had a tough time in your life ... we have to clear our souls. It is better to forgive and leave even the old animosity aside. After the earthquake, I forgot everything with one of our relatives whom I hated, and now we are commuting". (77-year-old woman).

\section{Self-regulatory behaviors}

After the earthquake, there were many changes in different parts of the elderly's life. Some accepted these changes and adjusted their behavior to the changes. These changes were sometimes more limited as a continuation of previous activities and sometimes as new behaviors. In some cases, these changes occurred in the elderly occupation:

"I used to have a lot of cows and sheep, which I sold after the earthquake, and I kept the sheep in the small warehouse I had. Now I earn a living with them". (67-year-old man).
Some of these changes were seen in daily activities:

"I have diabetes. I used to walk a lot every day, but when the earthquake hit and my back was injured, I could not do it like before, but I still have to walk daily" (72-year-old man).

\section{Relative reinforcing the houses}

Houses built after the earthquake were newer and stronger than previous dwellings, a kind of development.

"My previous house was big, but it was made of bricks and loose. These new houses are small, but their materials are strong, and they are engineered, and stronger houses" (61-year-old woman).

"The last house was made of mud. Every year something happened to the roof and walls, and I had to spend a lot of money to repair them. In the end, it was useless. This new house I have is more comfortable. It is stronger" (62-year-old man).

\section{Discussion}

The findings of the study showed that the changes in the lives of the elderly after the earthquake were put in the two main categories of re-victimization and post-accident growth. Re-victimization was caused by the experience of severe damage by the elderly in an earthquake, many of which could have been prevented or at least reduced if proper planning and measure had been taken.

In the area of physical-mental health declining, the findings of various studies have shown that with increasing age, the incidence of chronic diseases and disabilities increases. The elderly are more likely than others have chronic diseases such as arthritis, hypertension, heart disease, diabetes, and respiratory diseases so that $80 \%$ of people in this age group have at least one chronic disease, and $50 \%$ have at least two or more chronic problems [11]. The deterioration of the physical health of the elderly after the earthquake in the present study was also in many cases due to the lack of attention to pre-existing medical problems (such as lack of medication and care for chronic diseases). In various texts, a wide range of medical problems caused by earthquakes, such as worsening of chronic diseases, somatic symptoms, and high or low blood pressure and physical injuries in the elderly have been mentioned, which, if not addressed, results in many injuries [12-15]. 
In connection with the deterioration of mental health of the elderly after the accident, various studies have identified issues such as poverty, low level of education, life changes such as the loss of important people, and absence of psychosocial vulnerabilities of the elderly after the accident $[16,17]$. Besides, in the study of Alipour et al. (2014), factors such as non-native population immigration, suspension of calmness and spread of rumors, confusion, and uncertainty caused psychological reactions such as aggression, sleep disturbance, depression, and anxiety [18].

In the context of declining mental health, it should be borne in mind that some changes in the mental-emotional state related to accidents and disasters are acceptable and do not require follow-up. Still, some responses in the form of behavior beyond normal, excessive, and uncontrollable should be checked and followed up.

Another concept associated with re-victimization is the avoidance of work and family activities. The elderly experienced rapid, sudden, and unexpected changes in their work and family status after the earthquake. They lost many of their job facilities and necessities, which led to a sense of despair. On the other hand, the disarray of the living environment and the smaller houses caused the traditional social support networks for the elderly, such as the family and neighbors, have lost some of their effectiveness. In some cases, large families have become the nucleus, which has reduced their social interactions.

Under normal circumstances, the most group activities among the elderly living in Iran have been attending Quran meetings and religious delegations, followed by family and friendly gatherings, tourist and pilgrimage tours, and parks. These activities should be considered and planned for in the post-accident situation.

In addition, according to the findings of the present study, "increasing dependency" was another concept related to the idea of "re-victimization". In their research, Guttman et al. (2014) noted the dependence of the elderly after accidents and disasters in economic affairs, in daily activities, including housework (sweeping, washing, cooking, etc.) matters related to personal hygiene (baths, toilets, changing clothes, etc.) and instrumental daily life activities (activities that are somewhat more complex than normal daily activities and require a higher level of autonomy and ability to negotiate with the environment, such as shopping, repairing damaged roofs, and managing money) [20].

Other examples of the re-victimization of the elderly were poverty and deprivation. It seems that cases such as poverty before the earthquake, inability to restart jobs or learn new skills, ignoring them, and neglecting the allocation of relief and assistance services, etc., have been influential in the occurrence of poverty and deprivation. In this regard, some studies have pointed to the deprivation of the elderly from financial resources due to physical inability or lack of awareness $[21,22]$. The existence of some formal support mechanisms to facilitate their access to services seems to help prevent the deprivation of the elderly [23].

Findings from the study suggest that beyond the outcomes and opposite to re-victimization, there was the concept of "post-accident growth", meaning that the experience of the earthquake had led to individual growth for some older people and self-regulatory behaviors. They could adjust and continue their work and family situation following the changes that took place after the earthquake. They also became the owners of some new houses that were more resistant to the earthquake.

The experiences of the elderly in the present study showed that some elderly people experienced changes in the physical, mental/psychological, family, and social levels after the accident, which can be considered as a kind of "individual growth". Following the personal growth of relationships with others, the real meaning of life is re-evaluated, and life priorities are reconsidered [24]. Specific personal development areas can include increased patience, self-awareness, self-esteem, and a sense of calmness [25].

In addition, there seems to be a presumption that the elderly are helpless and in need of care in accidents and disasters. Still, the elderly are a very diverse group, and many of them take on the role of caring for and supporting young or disabled family members in the absence of other healthy people in accidents and disasters. Also, in cultures that traditionally respect the elderly, they help to establish peace among the younger, social justice, and the reshaping of society after an accident. And one of their most important roles is to preserve the culture and social identity of communities [9, 26]. Using the capacities and abilities of the elderly after accidents and disasters, in addition to collective benefits, helps them feel independent and self-confident and confident in their abilities in the elderly [9].

The last concept in relation to "individual growth" was the topic of "building stronger houses". The findings of the present study showed that after the earthquake, in some cases, new houses were built with better and more durable materials and in safer places. In some cases, the 
houses were rebuilt in the same dangerous and unsafe areas. According to this finding, in the study of Joakim et al. (2006), houses became stronger after the Yogyakarata earthquake [27].

\section{Conclusion}

According to the results of this study, the lives of the elderly change after the earthquake from re-victimization to post-accident growth. Given that many of the problems that the elderly faced after the quake could have been prevented with proper planning, disaster policymakers should consult with elderly specialists to make the necessary predictions in this regard. Besides, the elderly are a very diverse group, and some of them have different capacities in the field of work and family. Because of the lack of resources, it is possible to make the necessary predictions to use their abilities.

\section{Ethical Considerations}

\section{Compliance with ethical guidelines}

All ethical principles are considered in this article. The participants were informed of the purpose of the research and its implementation stages.

\section{Funding}

This research did not receive any grant from funding agencies in the public, commercial, or non-profit sectors.

\section{Authors' contributions}

All authors equally contributed to preparing this article.

\section{Conflict of interest}

The authors declared no conflict of interest.

\section{References}

[1] Gilmartin MJ, Spurlock WR, Foster N, Sinha SK. Improving disaster preparedness, response and recovery for older adults. Geriatric Nursing (New York, NY). 2019; 40(4):445. [DOI:10.1016/j.gerinurse.2019.07.006] [PMID]

[2] Shirazikhah M, Mousavi M, Sahaf R, Sarmadi M. Consequence of changes in the elderly people population: Elderly women in Iran. Life Science Journal. 2012; 9(4):869-77. http:/ / citeseerx.ist.psu.edu/viewdoc/download?doi=10.1.1.380.96 $41 \&$ rep $=$ rep $1 \&$ type $=$ pdf

[3] Almazan JU, Albougami AS, Alamri MS, Colet PC, Adolfo CS, Allen K, et al. Disaster-related resiliency theory among older adults who survived Typhoon Haiyan. International Journal of Disaster Risk Reduction. 2019; 35:101070 [DOI:10.1016/j.ijdrr.2019.101070]

[4] Mousavi SM, Zhu W, Sheng Y, Beroza GC. CRED: A deep residual network of convolutional and recurrent units for earthquake signal detection. Scientific Reports. 2019; 9(1):114. [DOI:10.1038/s41598-019-45748-1] [PMID] [PMCID]

[5] Almazan JU, Cruz JP, Alamri MS, Albougami ASB, Alotaibi JSM, Santos AM. Coping strategies of older adults survivors following a disaster: Disaster-related resilience to climate change adaptation. Ageing International. 2019; 44(2):141-53. [DOI:10.1007/s12126-018-9330-1]

[6] Timalsina R, Songwathana P. Factors enhancing resilience among older adults experiencing disaster: A systematic review. Australasian Emergency Care. 2020; 23(1):11-22 [DOI:10.1016/j.auec.2019.12.007] [PMID]

[7] Gibson MJ, Hayunga M. We can do better: Lessons learned for protecting older persons in disasters. Washington, D. C.: The National Academic of Sciences Engineering Medicine; 2006. https:/ / trid.trb.org/view/783156

[8] Alipour F, Khankeh HR, Fekrazad H, Kamali M, Rafiey H, Foroushani PS, et al. Challenges for resuming normal life after earthquake: A qualitative study on rural areas of Iran PLoS Currents. 2014; 6. [DOI:10.1371/currents.dis.b4e84b942500e2f8f260f3471b7ee815] [PMID] [PMCID]

[9] Johnson HL, Ling CG, McBee EC. Multi-disciplinary care for the elderly in disasters: An integrative review. Prehospital and Disaster Medicine. 2015; 30(1):72-9. [DOI:10.1017/ S1049023X14001241] [PMID]

[10] Alipour F, Khankeh H, Fekrazad H, Kamali M, Rafiey H, Ahmadi S. Social issues and post-disaster recovery: A qualitative study in an Iranian context. International Social Work. 2015; 58(5):689-703. [DOI:10.1177/0020872815584426]

[11] Lee DT. Quality long term care for older people: A commentary. Journal of Advanced Nursing. 2005; 52(6):609-19. [DOI:10.1111/j.1365-2648.2005.03629.x] [PMID]

[12] Eldar R. The needs of elderly persons in natural disasters: Observations and recommendations. Disasters. 1992; 16(4):355-8. [DOI:10.1111/j.1467-7717.1992.tb00416.x]

[13] Claver M, Dobalian A, Fickel JJ, Ricci KA, Mallers MH Comprehensive care for vulnerable elderly veterans during disasters. Archives of Gerontology and Geriatrics. 2013; 56(1):205-13. [DOI:10.1016/j.archger.2012.07.010] [PMID]

[14] Henderson TL, Roberto KA, Kamo Y. Older adults' responses to Hurricane Katrina: Daily hassles and coping strategies. Journal of Applied Gerontology. 2010; 29(1):48-69. [DOI:10.1177/0733464809334287]

[15] Uscher-Pines L, Vernick JS, Curriero F, Lieberman R Burke TA. Disaster-related injuries in the period of recovery: The effect of prolonged displacement on risk of injury in older adults. Journal of Trauma and Acute Care Surgery. 2009; 67(4):834-40. [DOI:10.1097/TA.0b013e31817f2853] [PMID]

[16] Montgomery E, Foldspang A. Traumatic experience and sleep disturbance in refugee children from the Middle East The European Journal of Public Health. 2001; 11(1):18-22. [DOI:10.1093/eurpub/11.1.18] [PMID] 
[17] Foa EB, Stein DJ, McFarlane AC. Symptomatology and psychopathology of mental health problems after disaster. The Journal of Clinical Psychiatry. 2006; 67(Suppl 2):15-25. https://d1wqtxts1xzle7.cloudfront.net/51863078/v67s0203_

[18] Alipour F. Social Rehabilitation after Azarbayjan Earthquake. Tehran: University of Social Welfare and Rehabilitation Sciences; 2014.

[19] Madah SB. The status of social and leisure time activities in the elderly residing in Iran and Sweden. Salmand: Iranian Journal of Ageing. 2008; 3(2):597-606. http:/ / salmandj.uswr. ac.ir/article-1-95-en.html

[20] Gutman GM YY. Elder abuse and neglect in disasters: Types, prevalence and research gaps. International Journal of Disaster Risk Reduction. 2014; 10(Part A):38-47. [DOI:10.1016/j.ijdrr.2014.06.002]

[21] World Health Organization. Ageing: WHO, Unit LC. WHO global report on falls prevention in older age. Geneva: World Health Organization; 2008. https://apps.who.int/ iris/handle/10665/43811

[22] Davey JA, Neale J. Earthquake preparedness in an ageing society: Learning from the experience of the Canterbury Earthquakes. Earthquake Commission. 2013; 2341. https:// ageconcerncan.org.nz/wp-content/uploads/2017/01/ Earthquake-preparedness-ageing-society.pdf

[23] Aldrich N, Benson WF. Disaster preparedness and the chronic disease nedds of vulnerable older adults. Preventing Chronic Disease: Public Health Research, Practice, and Policy. 2008; 5(1):1-7. https://pesquisa.bvsalud.org/portal/ resource/pt/des-17375

[24] Butcher HK, Holkup PA, Buckwalter KC. The experience of caring for a family member with Alzheimer's disease. Western Journal of Nursing Research. 2001; 23(1):33-55. [DOI: 10.1177/019394590102300104] [PMID]

[25] Lloyd J, Patterson T, Muers J. The positive aspects of caregiving in dementia: A critical review of the qualitative literature. Dementia. 2016; 15(6):1534-61. [DOI:10.1177/1471301214564792] [PMID]

[26] Peachey K. Ageism: A factor in the nutritional vulnerability of older people? Disasters. 1999; 23(4):350-8 [DOI:10.1111/1467-7717.00124] [PMID]

[27] Joakim E. Resilient disaster recovery: A critical assessment of the 2006 Yogyakarta, Indonesia earthquake using a vulnerability, resilience and sustainable livelihood's framework. Waterloo: University of Waterloo Library; 2013. https:/ / uwspace.uwaterloo.ca/handle/10012/7315 